\title{
INDUSTRIAL PARTNERS PROVIDE PROGRESS REPORT CARD FEEDBACK ON NEWLY DEVELOPED INDUSTRIAL CONTROL SYSTEMS LABORATORY
}

\author{
Jerome Tapper, Walter W. Buchanan \\ Northeastern University, Boston, Massachusetts
}

\begin{abstract}
In order for engineering technology programs to provide more formidable state-ofthe-art programs for their students, program administrators must gain insight into the worthiness of their curricula. Engineering technology programs and courses supported and evaluated by industry representatives are quite valuable in preparing students for responding to local and national market needs. After two years in development, a newly created Industrial Control Systems Laboratory supported in this manner, was implemented at Northeastern University's School of Engineering Technology in Boston, Massachusetts. This paper presents a brief history of the development and implementation of this laboratory course. More importantly, it provides interesting evaluation feedback from the industrial partners who supported this project since its inception through both state-of-the-art equipment donations valued at greater than \$500,000 as well as valuable feedback. Guidance from these important industrial resources is invaluable in making any midcourse corrections to the program and ensuring the material is relevant. This paper chronicles and outlines this process and shares the results with the reader.
\end{abstract}

\section{Background}

In the summer of 1998 during an informal lunch time meeting with the then director of engineering technology and the electrical engineering technology program coordinator, this author determined that a long overdue overhaul of the electrical engineering technology curricula was needed. Outdated existing courses coupled with declining program enrollments was leading to a severe decline in the Electrical Engineering Technology (EET) program.

In an effort to eliminate this situation, this author suggested the university create an innovative programming approach. The idea was to create a "new" group of courses that simultaneously utilized current technologies while also addressing a need in the industrial sector. It was a requirement that course related cooperative-work assignments play an integral role in this new curriculum. The idea was to not only create a new curriculum of courses, but a "new" and modern way of presenting the materials in these courses. This was the "birth" of the "LectureLaboratory" venue at Northeastern University. This venue allowed students to gain technical expertise via standard lectures along with "hands-on" experience during the same class period. It called for the application of the "engineering team" design process to solve design and application problems.

It was proposed that an Industrial Control Systems program be initiated as the first of these experimental courses. While clearly the concept had merit, there was legitimate concern about the cost of implementing such an idea. 
This author argued that to reverse the existing departmental downward trend required "out of the box" thinking. Moreover, since there appeared to be a serious lack of "degreed" engineers in the ICS industry, especially in the northeastern corridor of the United States, this program would be fulfilling a "real" industry need by providing this valuable and necessary resource. In fact, it was further reasoned that if this program was to be a main supplier of ICS engineering resources, industry themselves might be willing to support this program in some way. ${ }^{1,2}$

After much discussion, it was decided the basic goal of this program would be to provide stateof-the-art education in the area of industrial control systems, to include the exploration of as many ICS devices as time permitted. This would enable students to acquire the required skills to be placed as engineers in this particular industrial market. By providing students with an appropriate and current ICS technical education, in addition to associated cooperative work experience, all parties involved would benefit. Students, industry-employers, and the electricalengineering technology program at Northeastern University would all benefit in this win-winwin situation.

\section{Setting The Stage}

In order to successfully design new curricula, many existing obstacles had to be overcome. Among the questions that needed to be answered were:

\section{Space}

- What type of space requirement would be needed, and from where would it come?

- Who would fund the new laboratory infrastructure?

- Who would design the new laboratory setting?

\section{Equipment}

- What kinds of equipment would be required?

- Where would it come from?

\section{Consumables}

- Where would the ongoing monies come from for everyday consumables?

\section{Maintenance and Up-Keep}

- Who would maintain the new facility and where would the funding come from to do so?

These are just some of the issues that needed to be resolved over the course of the development of this new program. The focus of this paper is not to provide the details of this development, however, but to present a report card provided by industry as to how this program is doing with reference to meeting all of the original goals presented in the background section of this paper. 


\section{$\underline{\text { ICS Historical Development Timeline }}$}

- During the summer quarter of 1998 , a concerted effort was set into motion to find corporate benefactors for this new program. Contacts were made and a clear methodology was conceived to solicit prospective donors.

- State-of-the-art equipment was acquired through donations and educational-corporate relationships were established.

- Starting in the fall quarter of 1999 , a pilot course was configured and offered with six students taking part. This pilot course was provided with the help of industrial donors who graciously donated many thousands of dollars worth of equipment. There was a minimal expenditure for infrastructure, as an existing $225 \mathrm{sq}-\mathrm{ft}$ chemistry laboratory happened to be available which was gratefully utilized for this pilot experiment.

- The results of this pilot laboratory were overwhelming, as students responded more than favorably in both their coursework and course evaluations. This was the first time in the history of this author's teaching career that students did not want to leave after the threehour "lecture-laboratory" had ended.

- Subsequently to this, several additional laboratory courses were held in this facility. A proposal to the College of Engineering dean was made to assist in obtaining larger quarters for the successful endeavor.

- Major domestic and international ICS manufacturers were invited to the university for a presentation about the benefits of supporting the program. ${ }^{1,2}$

- Various Industrial Trade-Shows and Conferences were visited where industrial attendees were solicited for equipment donations and support.

- In June of 2000, the School of Engineering Technology was up for an ABET reaccreditation. The electrical engineering technology evaluator was given a tour of the "small" ICS facility and a glimpse of the "soon to be" new ICS facility. (Construction had not yet begun) The evaluator's response was extremely positive and predicted that the proposed new facility would soon be "too small" for appropriate use.

- By December of 2000, a 1,000 sq- $\mathrm{ft}$ area had been identified and construction had begun for the new ICS laboratory facility.

- Curriculum development was a collaborative effort between participating industrial benefactors/supporters and the university, which was very valuable in helping to gain important insight as to what industry felt was important with respect to class material. Further insight was gained as to how this material should be presented. In addition to supplying hardware and software, industrial corporate donors also supplied CDs and associated manuals and text materials to help support this instruction effort. ${ }^{3,4}$ 
- Two separate but interrelated ICS courses (lecture-laboratories) have since been developed and presented. Both of these courses have been presented twice in the new ICS laboratory facility.

- Industrial relationship building continues to be a high priority at the university, as stateof-the-art hardware and software is constantly undergoing change. It is important that the program keep fresh and current. Several new industrial partnerships are in the process of being forged, which will allow students to gain precious knowledge via co-operative work experience in alternate ICS areas.

\section{How Are We Doing?}

\section{The Survey}

On October 29, 2001, a survey intended to solicit feedback about the program was sent to thirty individuals of whom twenty-five were from ICS related industries (ICS donors included) and five were interested School of Engineering Technology faculty members. Of these, there were twenty industry respondents and three faculty respondents. This survey was designed to help determine if the program was meeting and/or exceeding expectations?

\section{Survey Rules}

- A rating scale, as shown below, followed each statement/question. The respondent was asked to circle the number that most closely represented their experience.

\section{Strongly Disagree}

12
3

\section{Strongly Agree}

5

- Each statement/question was followed by a space reserved for reviewer comment.

\section{The following statement was made at the end of the survey}

- Final Comments: Please make any comments that you feel are appropriate. Make your opinion known here. Without your critique, a more productive laboratory will be impossible. What do you think? How would you grade this program (as it is currently)? Has good progress been made in the short time frame it has been in operation (since the Spring of 2001)? What suggestions can you make that will make this program better? Don't be bashful here. I need your help!!! 


\section{Survey - Feedback Statements/Questions}

The following is a list of 31 statements/questions posed in this feedback survey.

1) Necessity for this program in general: A "real" need exists for a Bachelor of Science Degreed Engineering Technology program in the ICS area?

2) There is a serious lack of ICS workers in the marketplace in the Northeast corridor of the U.S.

3) The Northeast corridor of the United States (East Coast) could use a good "general" ICS teaching program.

4) The ICS industry as a whole has a potential void in the number of future available ICS workers.

5) The concept in the development of these courses as noted in the attached syllabi approaches what the market needs.

6) Students are more likely to specify components and products that they are familiar with.

7) Students find it easier to "learn by doing" rather than by simply reading and discussing concepts.

8) Potential ICS workers are more valuable when they have cooperative work experience in the ICS area.

9) The idea of a "lecture-laboratory" venue method of teaching appears to be a good technique when helping students' learn ICS concepts.

10) The layout of the "new ICS laboratory" as seen in the 5 Hayden Hall facility at Northeastern University is a good teaching forum model.

11) The topics as outlined in the two ICS course syllabi (see attached) contain good samples of topics for these two consecutive lecture-lab courses.

12) The equipment provided for the first ICS course, i.e., Siemens micro and mini PLCs along with various variable frequency drives, is a good representation of what students will encounter in the industrial world.

13) The equipment provided for the second ICS course, i.e., Cutler-Hammer's version of the "DeviceNet" control systems line along with various $\mathbf{C}+\mathbf{H}$ variable frequency drives, is a good representation of what students will encounter in the industrial world.

14) The concepts and applications of components such as "limit switches, proximity sensors, and photo-electric sensors" should be a requirement in courses such as these. 
15) Each of these "lecture labs" exposes students to real industrial applications via VHS video films of actual industrial applications of industrial control systems. This is a valuable learning tool.

16) Prior to any student's working with actual hardware/software, students are shown PowerPoint presentations to prepare them for the actual technical application of each ICS device. This appears to be an acceptable method of presenting ICS information.

17) Students in both ICS classes are "given-free" a CD ROM (with all files in pdf format) containing ALL of the ICS device manuals and application material related to that individual class. This is used for reference and allows the student to look up technical information related to a specific device to be applied. It also allows students to "review" material on their own at home. Students can learn more this way.

18) Students in the first ICS class are required to purchase a rather expensive textbook that contains programming material related to many different manufacturers' PLCs. This will allow each student to not only have a reference of the PLC that they are using in class, but also allow them to have an ongoing reference of many devices of which they may encounter in the industrial world. Students can benefit from such a text.

19) Students are required to "design" weekly (basic) ICS systems based on newly lectured materials that day. This gives students the "feel" of what real world pressure to complete a design is like.

20) Students are required to pass in weekly homework assignments containing selected problems and general questions from various textbooks. Related topics such as safety, correct hand-tool applications, and ICS device applications are among the information examined. This will help round out the student's knowledge of the ICS environment.

21) Organizational skills are important as students are required to prepare a paper "preliminary" design of their weekly projects prior to inputting programming data into a computer for download to the PLC or PC based ICS system. This helps develop a sense of predictability in the expected result. Students are taught to not rush by designing directly on the computer, but rather "do it on paper first" so that their time spent on a design is used efficiently and results can be somewhat predicted beforehand.

22) There are NO exams in either class since each student is required to demonstrate verbally directly to the instructor just what they are doing and how their design is to work. The instructor will critique their design and give them hints in the right direction. Many times students must seek the help of the device manual itself to determine how to implement it properly. Although they would want to be spoon fed answers, they are required to find it for themselves and then test it until successful. Students seem to learn better in this mode.

23) Students are divided into teams of two. "Two" seems to be the correct amount and allows each student to actively participate in the design concept and follow through. Each student team is made to feel as if they are in a design competition with the other 
teams. This seems to bring out the best in all of the students. Participation by each team member is a must if they are to achieve their weekly goal of a successful design. This does emulate the activities of industry where inter-department competition exists. All students want to be first and this drives their motivation to be successful.

24) Each lecture-laboratory is held once a week for three hours. This is the typical time frame for any 4 quarter-hour $(\mathrm{QH})$ course given at Northeastern University. The total inlab hours can range from 30 to 33 hours per quarter. This appears to be a sufficient amount of time for this lab.

25) Each team is required to hard-wire their own PLC Consoles or PC based ICS Consoles to I/O Load Consoles and Variable Frequency Drive Consoles when applicable. These consoles are designed so that students can interconnect them with 18 gauge MTW (Machine Tool Wire) via standard industry DIN rail mounted terminal blocks. Students are required to cut to length-strip and connect colored wires to each console. This gives students a sense of reality and allows them to participate in a needed ICS function.

26) Student teams are all presented with a FINAL design project to complete. This final design problem is presented from the viewpoint of a department manager speaking with his/her engineering design group. As part of their project, students are to prepare an extensive written report containing an organized presentation of their design and test work. They must also demonstrate the workability of their "team" design. All FINAL designs MUST WORK to be successful in either ICS course. After all, isn't that why they are here? This puts real world pressure on these students and will better prepare them for the industrial environment.

27) As state-of-the-art equipment changes, additional ICS courses may need to be created. This will allow students to add additional ICS information to their knowledge base and keep up with current ICS activities.

28) This lab facility was designed to create a dual environment. This dual environment is a classroom for lectures and an active laboratory for actual hardware/software application and presentation. Being such, the floor has been totally rugged so that students get a "warm" feeling implying a classroom environment. A rectangular section of rug has been removed from the center of the room (looks like a small dance floor) to accommodate the development of industry supplied student projects. This open area is a staging area for these projects and allows students to have these projects on a tiled floor to simulate a factory floor setting (it also helps to protect the rug from large equipment damage). In addition, the entry doors to this facility are large opening double doors also known as 1 $1 / 3$ doors. This is to allow larger equipment to be brought into the facility to be placed on the staging area floor. It is believed that this type of infrastructure is very conducive to providing the student with the look and feel of a real industrial floor environment. Do you agree?

29) To this point, we are currently using only the Siemens Micro-PLCs. The reason for this is that training stations take a lot of time to construct and wire. This program has limited resources for this construction. This facility currently has nine additional "Mini PLC" 
trainers, but these have not been wired yet. This will take place in the winter quarter of 2002. When completed, students will have the opportunity to not only work with the existing micro-PLCs, but will also see how to use their big brothers -the mini-PLCs. This will go a long way toward providing additional re-enforcement to the topic of the PLC and its programmability and application.

30) To this point, we are currently using nine Cutler-Hammer DeviceNet control systems. These systems will also see their components assembled into professional workstation trainers in the winter quarter of 2002. Currently, these devices are open wired on benches allowing students to program and test their capability. This has not hampered the ability of students to learn this ICS system, but it is felt that by placing these devices on a more organized platform such as a training unit, students will gain a more organized approach to their use.

31) During the course of an academic quarter, guest lecturers from industry are invited to speak to students in these classes. It is believed that by providing "live" industry speakers, students will have the concepts that they have learned re-enforced. It is one thing for an instructor to babble on about ICS systems and another to actually have someone else come in and re-enforce these ideas.

\section{Corporate Survey Participants}

- Siemens Energy and Automation

- Cutler-Hammer Corporation

- Controller Services Corporation

- Empire Automation, Inc.

- Atlantic Reliability Corporation

- Fraen Corporation

- Micron Medical Products, Inc.

- Empire Alarm Co., Inc.

- Parkinson Machinery and Manufacturing Corporation

- Verizon Corporation

- Walco Electric Co., Inc.

The authors would like to gratefully acknowledge the employees of these corporations who so graciously gave of their time in completing this survey. 


\section{Survey Results}

17-Dec-01

Industrial Control Systems Laboratory Curriculum Survey Data Feedback

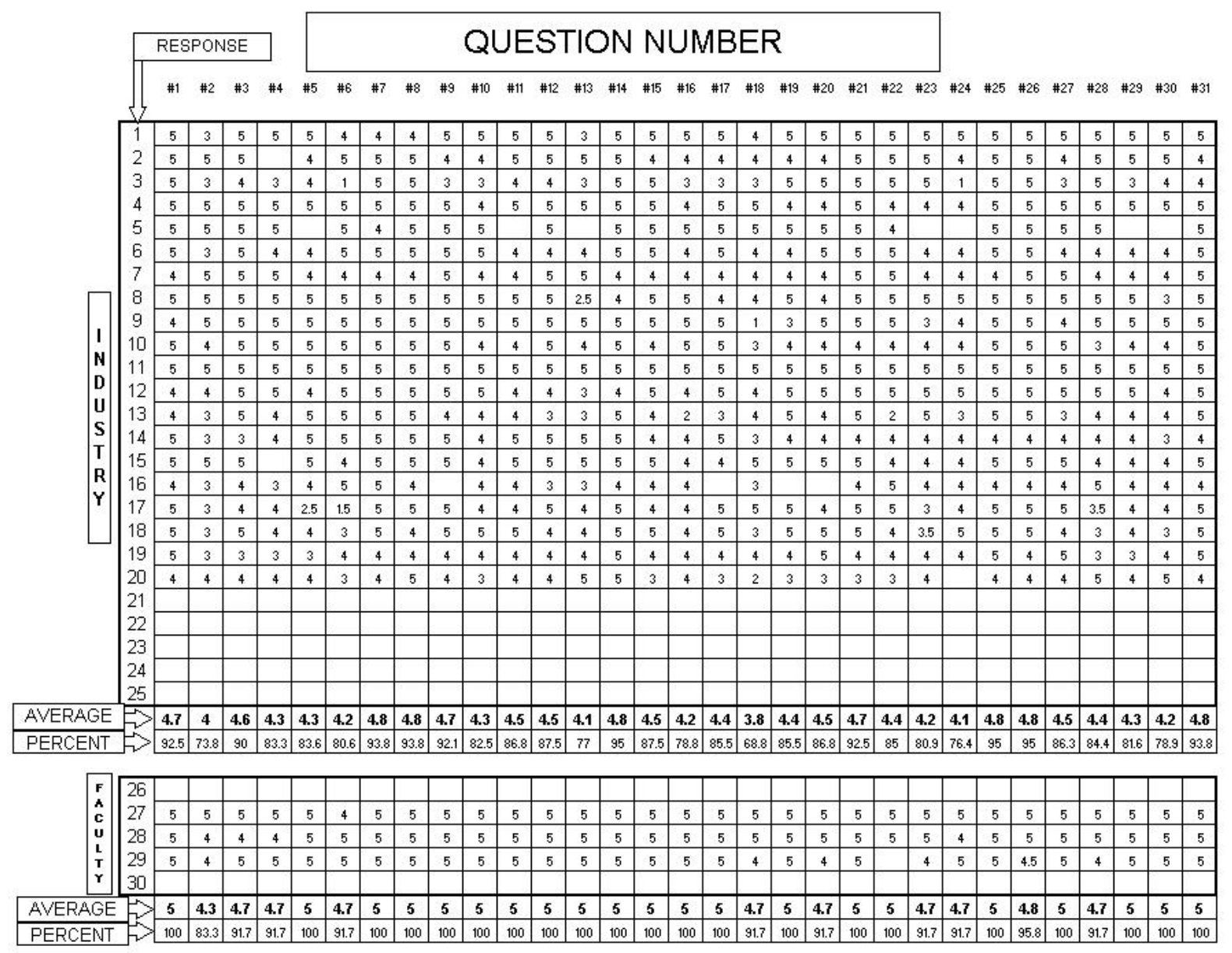

Table 1

Summary of Respondent's Feedback Ratings

\section{Reviewing The Data}

\section{Analysis}

Respondents' data is presented in tabular form in Table 1. For clarity and analysis purposes, the information was divided into two groups - an industry and a faculty group. The average response to each question for each group is also displayed, as is the statistical percentage average ratings for each question. To get a clearer understanding and picture ${ }^{5}$ of what has taken place, bar charts have been created showing the importance of these questions relative to each other. These are shown in Figures 1, 2 and 3. Since "One Picture is Worth a Thousand Equations"," these charts reveal much about the individual likes and dislikes of the program reviewers. 


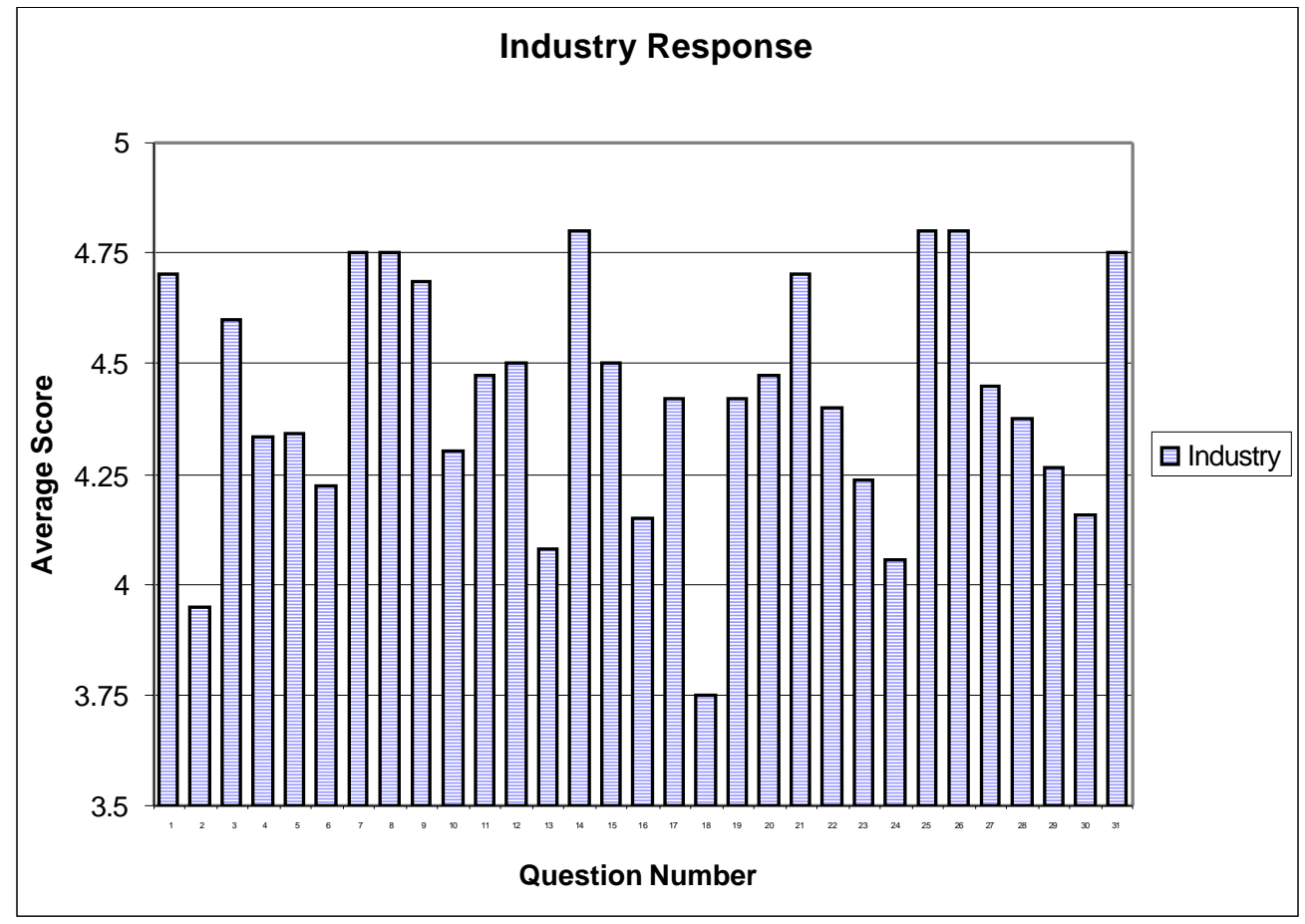

Figure 1 Industry Respondent's Feedback Survey Average Values

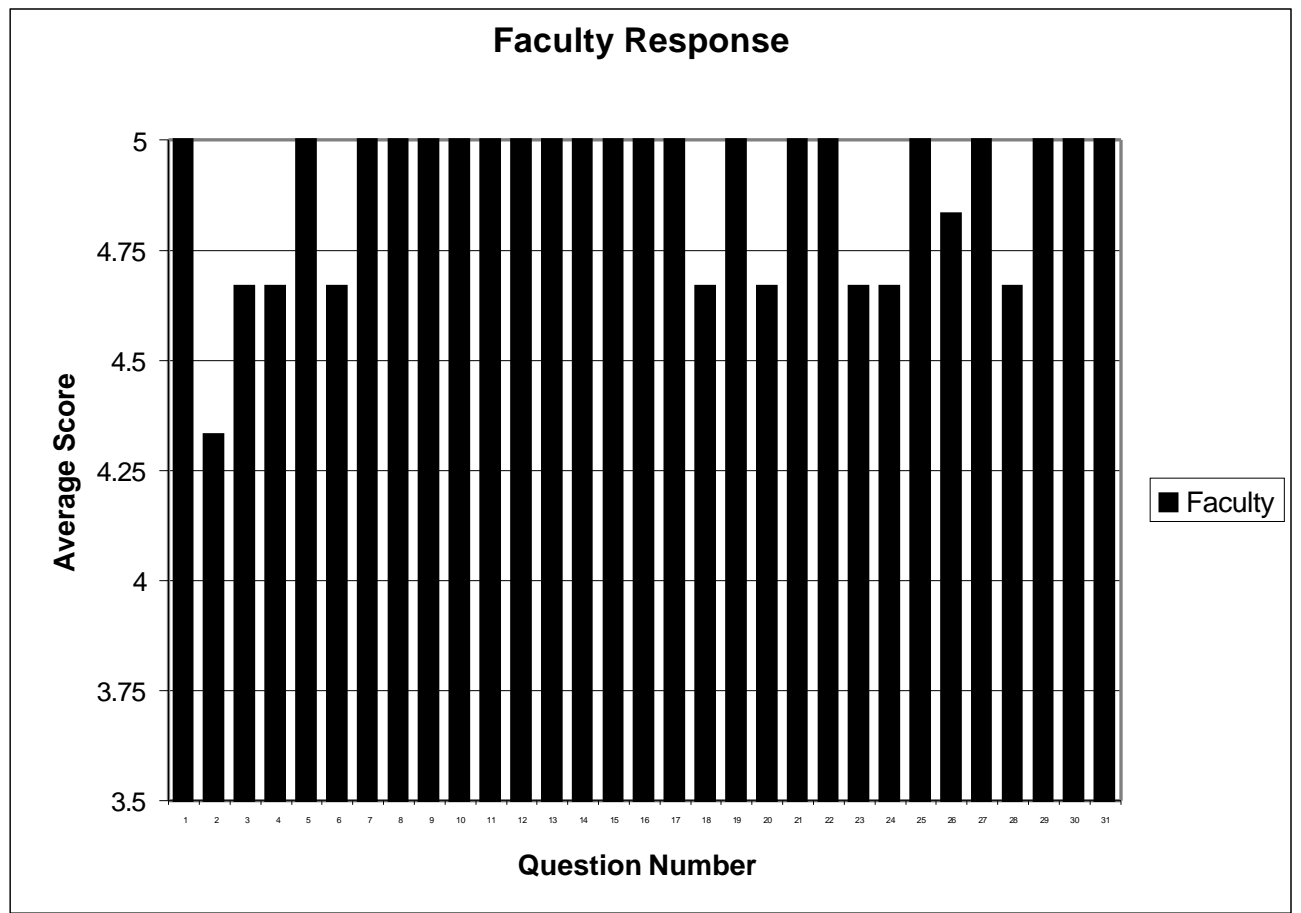

Figure 2 Faculty Respondent's Feedback Survey Average Values 


\section{Survey Group Differences}

As can be seen graphically in Figure 3, there seems to be some difference in opinion between the "industrial-group" and the "faculty-group." It seems that the faculty group has given the program higher marks than the industrial group in ALL categories. One possible implication of this finding is that the faculty group would have us believe that the curriculum "as designed" is satisfactory. The industrial group seems to feel that there is always room for improvement, since they have consistently given program marks lower then the faculty group. In fact, since they have consistently scored average numbers lower than five implying that they do not totally agree with some of the areas in the program as currently designed.

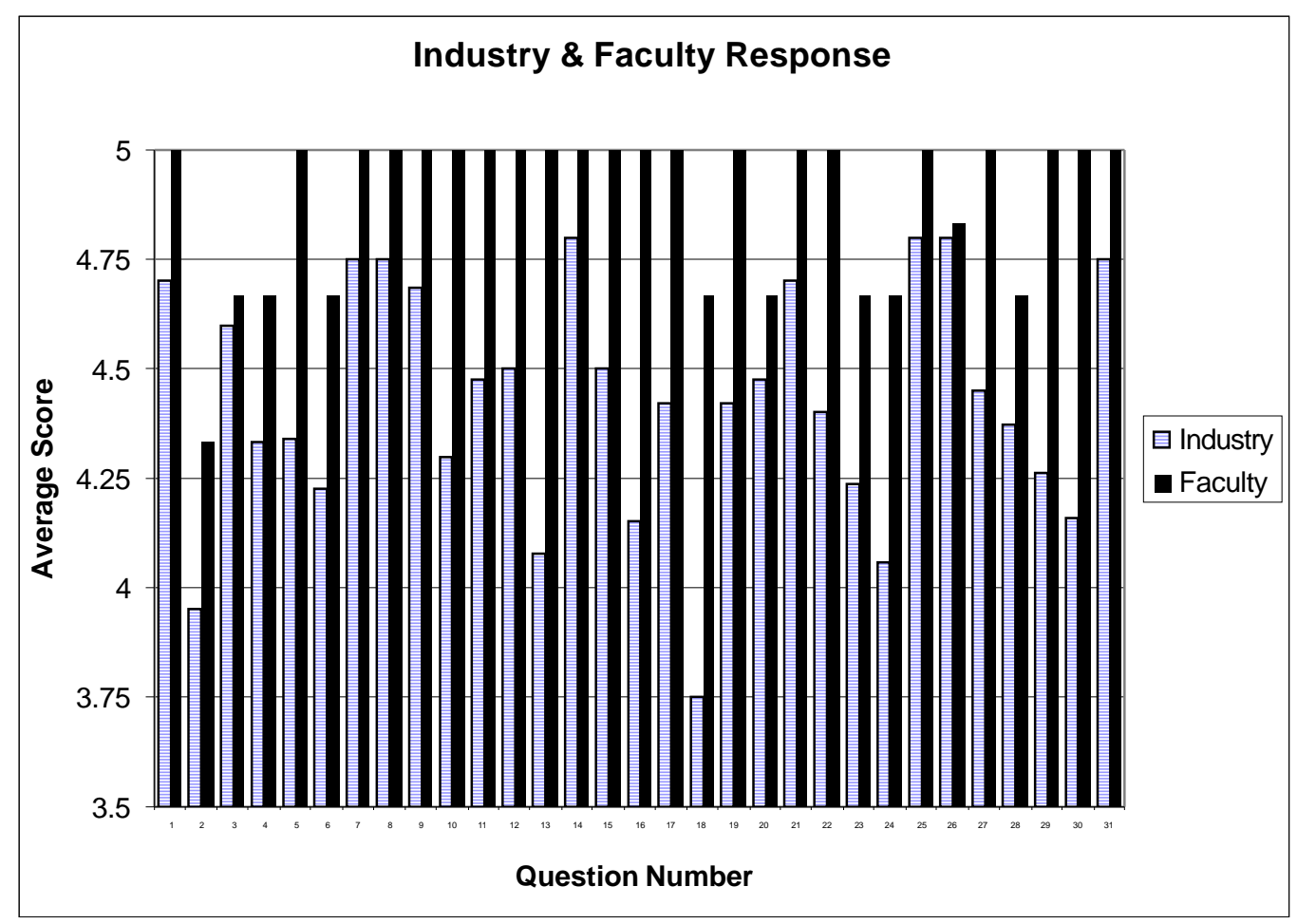

Figure 3 Industry/Faculty Respondent's Feedback Survey Average Values Compared

One can only speculate about the reasons for the discrepancies between these two groups. It is quite probable that the faculty group may very well be looking at this from a somewhat industrially inexperienced, yet academic prospective. The authors feels that more creditable criticism would most likely come from the people who actually are the "most" experienced in their ability to know what they want by virtue of their personal experience with their own workforce personnel. Think about it - if you were an engineering manager who was responsible for the management of high-level projects and had the ability to screen hiring candidates who would be working on these projects, would you not know what you were looking for in a candidate? Of course you would! It only seems natural that an industry manager, if asked, would be clear about the skills/experience that would be needed by their future employees.

Furthermore, it seems natural that they would understand what should be required in a good ICS curriculum versus a mediocre one. It is for this reason and the fact that the "industry-group" 
reviewers' data did NOT yield any averages of "five" (the maximum). This may imply that that the survey numbers from the industry respondents are probably more credible than other groups.

\section{Data Groups}

From a review of the industry-group survey responses as seen in Figure 1, marks can be divided into three data groups, the $G O O D$, the $B R O A D$, and the $U G L Y$. The regions are given as:

\section{The GOOD}

- The top percentage getters in the range of "95\%" and above were limited to three questions 14, 25 and 26. The authors feel that these categories are sufficient and need virtually no change.

\section{The $B R O A D$}

- There were many responses to questions residing in the " $80 \%$ " to "94\%" region. These were $4-12,15,17,19-23,27-29$, and 31 . Topics of these survey questions need to be reviewed in concert with the industrial respondents survey comments. It is felt that since the majority of marks fall into this category, some minor "program tweaks" need to be performed in these areas.

\section{The UGLY}

- Sadly, there were several lower program marks in various areas. These marks ranged from "68.8\%" to "78.9\%. These were 2, 13, 16, 18, 24, and 30. Although these survey statement/questions were observations by the author and felt to be true, the consensus of industry respondents was quite the opposite. For example:

Question 2 deals with an observation that there is a "serious lack" of ICS workers in the U.S. It would appear that this is in dispute by the respondents. There were mixed comments here.

Question 13 deals with the perception that certain equipment is representative of what students will see in the real world. Again, from the individual marks given by respondents as seen in Table 1, it appears that there are some differences of opinion. Upon further study of the individual marks, it seems that these grades were given along "partial" vendor lines. That is, the respondents who were vendors of the products in question agreed with the original question, but it appears that responding vendors of alternate competitive products disagree.

Question 16 deals with whether students can learn from the use of PowerPoint presentations. Admittedly the marks given for this question has this author baffled. According to respondent's comments, the majority said that this is what was used in industry and was a good teaching tool. Yet, the score was low! The marks definitely contradict the comments.

Question 18 deals with the requirement that students purchase an expensive reference text. The marks were indeed low, but there were many comments that gave praise to this idea. It is probably a good idea to NOT require this again and find an alternate, less expensive, method of providing reference material. 
Question 24 deals with the amount of time required for each lecture-lab course. This received low marks and was substantiated by respondent comments implying that this course should have longer sessions. This is something with which this author also agrees.

Question 30 deals with constructing more formal training stations for one of the ICS products to be taught here. This author is somewhat baffled by the low score and in fact disagrees with the score of the respondents. It is felt that there may be the possibility of some confusion in the wording of this question in the survey. Further discussion with respondents is in order here.

\section{$\underline{\text { Summary }}$}

Feedback, both positive and negative, is a good thing. It has been said that we cannot know where we are going if we do not know where we have been. This survey will greatly aid in the search for the elements necessary to build an ICS curriculum that will provide students the necessary tools to be productive and "valuable" engineering technologists in the workplace. Although the survey was somewhat long and tedious, it has helped to answer many questions that could not have otherwise been answered without the depth that this survey provided. There is no clear-cut approach to creating and maintaining a quality ICS program, but one thing is clear-industry opinions are needed to help untangle the web of confusion that exists when a program of this sort is conceived and implemented. Constructive criticism is, and will always be, needed to improve curricula. Without such commentary, narrow minded and limited curricula will result. The lesson to be learned here is to "always listen" to the experienced experts - in this case, professional industry representatives.

\section{$\underline{\text { References }}$}

${ }^{1}$ Tapper, Jerome, "Building Industry Partnerships, The Key to Creating State-of-the-Art Laboratories," Proceedings of CIEC, Presented February, 2000, Orlando, FL, Session CIP/ETD 345

${ }^{2}$ Tapper, Jerome, "Building Industry Partnerships by Enticing Industry to Work for You," Proceedings of A.S.E.E., Presented June, 2000, St. Louis, MO, Session 2647

${ }^{3}$ Tapper, Jerome, "Creating Industrial Partnered Curriculum, A Work in Progress," Proceedings of CIEC, Presented February, 2001, San Diego, CA, Session ETD 345-3

${ }^{4}$ Tapper, Jerome, "Industry Driven Curriculum Development, the Key to Successful Courseware," Proceedings of A.S.E.E., Presented June, 2001, Albuquerque, NM, Session 3247

${ }^{5}$ Tapper, Jerome / Buchanan, Walter, "One Picture is Worth a Thousand Equations, Multimedia in the Classroom is Worth its Weight in Gold," Proceedings of CIEC, Presented February, 2002, Sarasota, FL, Session 4424

\section{JEROME TAPPER}

Professor Tapper is an Associate Academic Specialist in EET at Northeastern University in Bost on, Massachusetts. He holds a BSEE and an MSIS, both from Northeastern University. Jerry is a Registered Professional Engineer in the Commonwealth of Massachusetts with over twenty-five years of industrial experience. He is also the author of a tool-kit based text for electrical engineering technology students, Electronics for Engineering Technology.

\section{WALTER W. BUCHANAN}

Dr. Buchanan is Professor of Electrical Engineering Technology and Director of the School of Engineering Technology at Northeastern University. He received his BSE and MSE from Purdue University, and his Ph.D. and J.D. from Indiana University. Walt is a P.E. in five states, and is Past Chair of the Engineering Technology Division of ASEE. He has written 80 papers, and is a Member of TAC of ABET and Past Chair of IEEE's CTAA. 